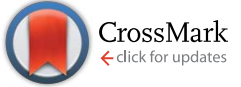

Cite this: Anal. Methods, 2015, 7, 2699
Received 10th December 2014

Accepted 9th February 2015

DOI: $10.1039 / c 4 a y 02929 a$

www.rsc.org/methods

\section{Mercury(II) and methylmercury determination in water by liquid chromatography hyphenated to cold vapour atomic fluorescence spectrometry after online short-column preconcentration}

\author{
S. Carneado, R. Peró-Gascón, C. Ibáñez-Palomino, J. F. López-Sánchez \\ and A. Sahuquillo*
}

This paper reports a method developed for the simultaneous determination of methylmercury $\left(\mathrm{MeHg}^{+}\right)$and mercury(॥) $\left(\mathrm{Hg}^{2+}\right)$ species in water by liquid chromatography coupled to online UV irradiation and cold vapour atomic fluorescence spectrometry (LC-UV-CV-AFS) after online short-column preconcentration. This work focused on systematic studies of several variables to establish the maximum species recoveries, preconcentration factors and good reproducibility. The optimum results obtained were the following: $0.07 \mathrm{mmol} \mathrm{L}^{-1}$ 2-mercaptoethanol as a complexing agent, precolumn conditioning with the mobile phase: a mixture of $80 \%$ of methanol $(\mathrm{MeOH})$ and $20 \%$ of the following buffer: $0.0015 \mathrm{~mol} \mathrm{~L}^{-1}$ ammonium pyrrolidine dithiocarbamate (APDC) and $0.01 \mathrm{~mol} \mathrm{~L}-1$ ammonium acetate $\left(\mathrm{NH}_{4} \mathrm{CH}_{3} \mathrm{COO}\right)$ at $\mathrm{pH} 5.5,2 \mathrm{~cm}$ precolumn length and $2 \mathrm{~mL} \mathrm{~min}^{-1}$ sample flow. This method was applied to three water samples with different mineralisation contents. Various tests, based on spikes, were performed on each sample. A breakthrough volume of $4 \mathrm{~mL}$ was found. The recovery values of $72 \pm 3 \%$ and $81 \pm 5 \%$ for $\mathrm{MeHg}^{+}$and $\mathrm{Hg}^{2+}$, respectively, were obtained regardless of the matrix composition, and the PF values were 30 and 32 for $\mathrm{MeHg}^{+}$and $\mathrm{Hg}^{2+}$, respectively. The accuracy of the preconcentration method was verified by analysing a certified reference material. The detection limits (LDs) obtained were $15 \mathrm{ng} \mathrm{L^{-1 }}$ for $\mathrm{MeHg}^{+}$and $2 \mathrm{ng} \mathrm{L}^{-1}$ for $\mathrm{Hg}^{2+}$. The quantification limits (LQs) were $50 \mathrm{ng} \mathrm{L}^{-1}$ for both species. The established analytical online preconcentration method is suitable for the quantification of mercury species in a wide range of environmental waters.

\section{Introduction}

The determination of mercury species in environmental samples is of global concern, because of their natural persistence in the environment and the distinct mechanisms whereby they change their chemical form, ${ }^{1}$ which affects their distribution and toxicity. The most relevant species in the environment are elemental mercury $\left(\mathrm{Hg}^{0}\right)$, mercury(II) $\left(\mathrm{Hg}^{2+}\right)$, monomethylmercury $\left(\mathrm{CH}_{3} \mathrm{Hg}^{+}\right.$, $\mathrm{MeHg}^{+}$), dimethylmercury (DMeHg) and monoethylmercury $\left(\mathrm{EtHg}^{+}\right)$. Organic mercury compounds tend to be much more toxic than mercury(II), and mercury(II) is more toxic than the elemental form. $\mathrm{MeHg}^{+}$is the form in which mercury accumulates and biomagnifies in the aquatic food chain due to its high liposolubility. ${ }^{2}$ It is absorbed, transported through biological membranes and accumulated in nerve cells. Due to the decrease in the production and use of organomercurials, methylmercury $\left(\mathrm{MeHg}^{+}\right)$is by far the most common organomercury compound in the environment. ${ }^{3}$

Mercury is released into the environment from both natural sources and as a result of human activities. Once it has entered

Departament de Química Analitica, Universitat de Barcelona, Martí i Franqués, 1-11, o8028 Barcelona, Spain. E-mail: angels.sahuquillo@ub.edu; Tel: +34934039274 the environment, mercury cycles occur between air, land and water. In these cycles, mercury species may be converted. ${ }^{1} \mathrm{~A}$ relevant transformation process in aquatic environments is the conversion of mercury(II) into monomethylmercury by microorganisms and microalgae. ${ }^{4}$ Therefore, water is one of the most relevant studied environmental compartments. It not only has a great impact on the environment, but also on human health because safe water is essential to human activity.

The European Water Directive, ${ }^{5}$ which seeks to establish a framework for the protection of groundwater and surface water, includes mercury and its compounds in a list of priority and hazardous substances. Therefore, it is one of the elements to be considered in the evaluation of the status of physico-chemical water quality. However, at present, the European Drinking Water Directive considers only total mercury concentration, and

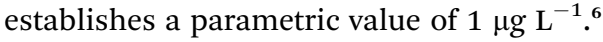

Mercury concentrations in water are expected to be very low. ${ }^{7}$ Besides, methylmercury levels tend to be much lower than those of mercury(II), due to the decomposition of organic compounds by solar UV light and the difficulty of methylation reactions in the aqueous phase. The mean reported for the $\mathrm{Hg}$ concentration in water is $2 \mathrm{ng} \mathrm{L}^{-1}$. ${ }^{\mathrm{T}}$ The $\mathrm{MeHg}^{+}$concentration corresponds to $1 \%$ of 
this value, and the rest is mercury(II). The concentration of mercury is normally in the range of $1-20 \mathrm{n} \mathrm{L}^{-1}$ in open-ocean water, while up to $100 \mathrm{ng} \mathrm{L}^{-1}$ is usually found in coastal water, owing to anthropogenic discharges. ${ }^{9}$ In the literature, analytical methods using CV-AFS or CV-AAS detectors without a preconcentration step have limits of quantification higher than the $\mathrm{Hg}$ concentrations in water. ${ }^{3,10-13}$ Therefore, because of the extremely low concentrations of mercury in this type of sample, highly sensitive, simple and rapid methods are required. Consequently, preconcentration systems need to be developed.

Several extraction and preconcentration methods have been reported for the enrichment of mercury species applied mainly in environmental waters. The main approaches for the preconcentration of trace elements from water are liquid-liquid extraction (LLE) ${ }^{14}$ and solid phase extraction (SPE). Comparatively, SPE is more environmentally friendly, as it is free of toxic organic extraction reagents. Most importantly, its stronger tolerance to complex matrices endows it with better capability of online applications. ${ }^{9}$ In solid phase extraction as a preconcentration step, C18 cartridges have been the most widely used stationary phase, both directly and after derivatisation ${ }^{15-24}$ with a wide range of complexing agents, most of which contain sulphur, such as 2-mercaptoalcohols, dithiocarbamates, dithizones, triazenes, and even bacteria. ${ }^{15-32} \mathrm{~A}$ wide variety of eluting agents have also been used to desorb mercury species from the stationary phase, such as acidic solutions, thiourea solutions, mobile phases with organic-modifiers, aqueous solutions with a reagent containing sulphur, and even a mixture of these kinds of solutions with an organic solvent, among others., ${ }^{9,14-35}$

After elution, a separation procedure has sometimes been applied. In some cases, gas-chromatography or liquid chromatography was performed to separate mercury species. ${ }^{9,15-18,20-22,24,25,29,33,36}$ In others, selective retention or elution of mercury species was carried out using different complexing agents or eluting agents for each species. ${ }^{19,26,28,30,31,34,35} \mathrm{~A}$ wide variety of detectors have been used, either for offline preconcentration or online flow injection preconcentration. Ultraviolet detection (UV), ICP-MS and atomic absorption or fluorescence spectrometry with cold vapour generation (CV-AAS and CV-AFS) are the most relevant systems of detection reported., ${ }^{9,-24,26-36}$ ICP-MS is the most sensitive of these detection methods. However, an online preconcentration system coupled to CV-AFS could provide a similar analytical performance by using a simpler set-up and with a lower investment.

As the reported methods for the mercury preconcentration are mainly applied to natural waters, such as sea, river, spring, lake, rain and underground waters, among others, there is a lack of studies applied to drinking water. A few studies are applied to tap water. Thus, the aim of this paper is to develop an online method for mercury(II) and methylmercury determination by high-performance liquid chromatography hyphenated to cold vapour atomic fluorescence spectrometry after shortcolumn preconcentration. The established method was applied to determine mercury species in drinking water samples of different matrix compositions, including a certified reference material of wastewater.

\section{Experimental}

\section{Instrumentation}

The LC system consisted of a quaternary pump and degasser (Agilent Technologies 1100, Waldbronn, Germany), equipped with a manual stainless steel sampler injector (Rheodyne Model 7725i) and a $100 \mu \mathrm{L}$ sample loop.

The separation of mercury species $\left(\mathrm{Hg}^{2+}\right.$ and $\left.\mathrm{MeHg}^{+}\right)$was achieved in an analytical RP-C18 column (ODS Hypersyl 250 $\mathrm{mm} \times 4.6 \mathrm{~mm}$ id, $5 \mu \mathrm{m}$, Thermo Hypersil-Keystone).

After separation, a photo-oxidation step was performed in a 12 meter length $\times 0.5 \mathrm{~mm}$ id PTFE tube coiled around a UV lamp with a power irradiation of $150 \mathrm{~W}$ (Heraeus TQ 150).

The reduction step was achieved in a cold vapour generator (CV) 10004 (P.S. Analytical, Orpington, UK), in which the effluent was mixed with the reducing agent. The metallic mercury vapour that was obtained reached the gas-liquid separator, from which it was dragged into the detector by an argon stream (300 $\mathrm{mL} \mathrm{min}^{-1}$ ) and dried in a PermaPure membrane with nitrogen $\left(2.5 \mathrm{~L} \mathrm{~min}^{-1}\right)$. Measurements were carried out using a Merlin Mercury Atomic Fluorescence Detector model 10023 (P.S. Analytical).

\section{Reagents and standards}

Only analytical grade reagents were used. The standards and reagents in this study were prepared with doubly deionised water (Elix \& Rios 5-15 M $\mathrm{cm}^{-1}$, total organic carbon $<30 \mu \mathrm{g}$ $\mathrm{L}^{-1}$ ) obtained from a Milli-Q water purification system (Millipore, Bedford, MA, USA).

A mercury(II) stock standard solution of $1000 \mathrm{mg} \mathrm{L}^{-1}$ was prepared by dissolving appropriate amounts of mercury chloride and $\mathrm{HgCl}_{2}$ (Merck, Darmstadt, Germany) in $1 \%(\mathrm{v} / \mathrm{v}) \mathrm{HNO}_{3}$, from nitric acid 69\% (Panreac, Hiperpur). A methylmercury stock standard solution of $1000 \mathrm{mg} \mathrm{L}^{-1}$ was prepared by dissolving appropriate amounts of $\mathrm{CH}_{3} \mathrm{HgCl}$ (Carlo Erba, Milan, Italy) in 3\% methanol (Panreac, p.a.). All stock standard solutions were stored at $4{ }^{\circ} \mathrm{C}$. The working standard solutions were prepared daily from the stock standard solutions by appropriate dilution.

For the cold vapour generation, $\mathrm{SnCl}_{2}$ solution was prepared daily from tin chloride 2-hydrate (Panreac, p.a.) to $1.5 \%$ concentration, in $4 \%$ of $\mathrm{HCl}$, from hydrochloric acid $35 \%$ (Panreac, Hiperpur).

The mobile phase was prepared daily by dissolving appropriate amounts of ammonium pyrrolidine dithiocarbamate, APDC (Fluka, p.a.), ammonium acetate, and $\mathrm{NH}_{4} \mathrm{CH}_{3} \mathrm{COO}$ (Merck, p.a.) in water. The $\mathrm{pH}$ was adjusted to 5.5 with diluted acetic acid (Panreac, p.a.) and then filtered on a $0.45 \mu \mathrm{m}$ filter paper (Millipore type HA). The final mobile phase composition was a mixture of $80 \%$ of $\mathrm{MeOH}$ LC gradient grade (Panreac, p.a.) and the prepared buffer: $0.0015 \mathrm{~mol} \mathrm{~L}^{-1}$ APDC and $0.01 \mathrm{~mol} \mathrm{~L}^{-1} \mathrm{NH}_{4} \mathrm{CH}_{3} \mathrm{COO}$.

For the preconcentration step, appropriate amounts of 2mercaptoethanol and APDC (Fluka, p.a.) were used as a complexing agent for mercury species in working solutions and water samples.

Certified reference material (CRM) of wastewater effluent acidified with $\mathrm{HNO}_{3}$ to about $\mathrm{pH} 2$ to stabilise the trace 
amounts (ERM-CA713) was used for quality control. It was obtained from the Institute for Reference Materials and Measurements of the European Commission's Joint Research Centre, Geel, Belgium.

\section{Samples}

Three samples, tap water and weak and strong mineralised bottled waters, were filtered through a filter with a pore size of $0.22 \mu \mathrm{m}$. The origin, $\mathrm{pH}$ and conductivity values for each sample after filtration are shown in Table 1, together with some anion and cation content determined by anionic exchange

Table 1 Characteristics of the water samples tested

\begin{tabular}{lllc}
\hline & $\begin{array}{l}\text { Weak } \\
\text { mineralised } \\
\text { water }\end{array}$ & $\begin{array}{l}\text { Strong } \\
\text { mineralised } \\
\text { water }\end{array}$ & Tap water \\
\hline $\mathrm{pH}$ & 6.8 & 7.8 & 8.1 \\
$\mathrm{Conductivity}\left(\mu \mathrm{Sm}^{-1}\right)$ & 66 & 767 & 547 \\
$\mathrm{Cl}^{-}\left(\mathrm{mg} \mathrm{L}^{-1}\right)$ & 1.8 & 7.1 & 34.1 \\
$\mathrm{~F}^{-}\left(\mathrm{mg} \mathrm{L}^{-1}\right)$ & 0.06 & 0.16 & 0.10 \\
$\mathrm{NO}_{3}{ }^{-}\left(\mathrm{mg} \mathrm{L}^{-1}\right)$ & 1.7 & 0.56 & 5.6 \\
$\mathrm{SO}_{4}{ }^{2-}\left(\mathrm{mg} \mathrm{L}^{-1}\right)$ & 5.5 & 120 & 43.5 \\
$\mathrm{Ca}^{2+}\left(\mathrm{mg} \mathrm{L}^{-1}\right)$ & 3.2 & 94 & 52.9 \\
$\mathrm{Mg}^{2+}\left(\mathrm{mg} \mathrm{L}^{-1}\right)$ & 3.5 & 43 & 9.0 \\
$\mathrm{Na}^{+}\left(\mathrm{mg} \mathrm{L}^{-1}\right)$ & 1.6 & 7.7 & 20.7 \\
$\mathrm{~K}^{+}\left(\mathrm{mg} \mathrm{L}^{-1}\right)$ & 1.4 & 2.5 & 3.3
\end{tabular}

\section{Preconcentration system}

A previously developed and validated LC-UV-CV-AFS method for the separation of mercury species was adapted. The experimental conditions of the hyphenated technique are described in study of Ibáñez-Palomino et al. ${ }^{3}$

In order to couple the online preconcentration system prior to LC-UV-CV-AFS, the original sample loop was replaced with a short RP C18 precolumn with the same characteristics as the separation column: ODS Hypersyl 10, 20 or $50 \mathrm{~mm} \times 4.6 \mathrm{~mm}$ id, $5 \mu \mathrm{m}$, Thermo Hypersil-Keystone, which was connected by an isocratic LC pump (Agilent Technologies 1260, Waldbronn, Germany) and a six channel valve (Rheodyne model 7000 6-port). This system alternates the sample flow and the mobile phase passing through the precolumn, which allows the loading of different sample volumes to the precolumn, so as to preconcentrate mercury species. When the valve is in the loading position, the sample passes through the precolumn and mercury species are adsorbed onto the stationary phase. In the injection position, the mobile phase passes through the precolumn and elutes the retained mercury species to the LC-UV-CV-AFS system for determination. a)

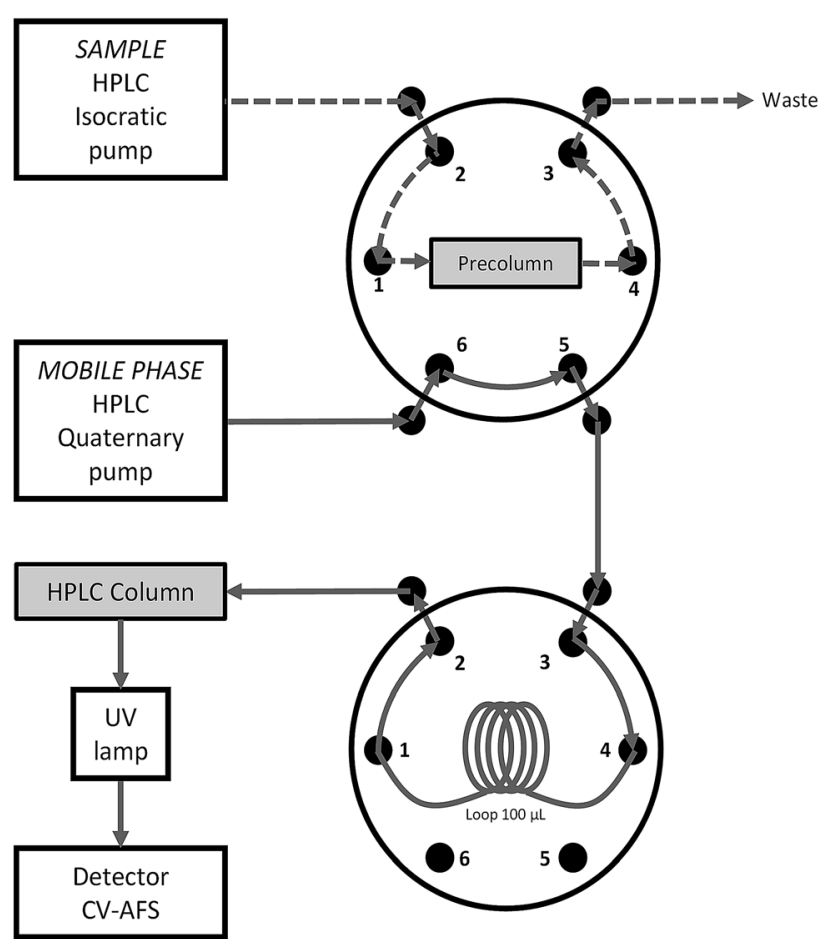

b)

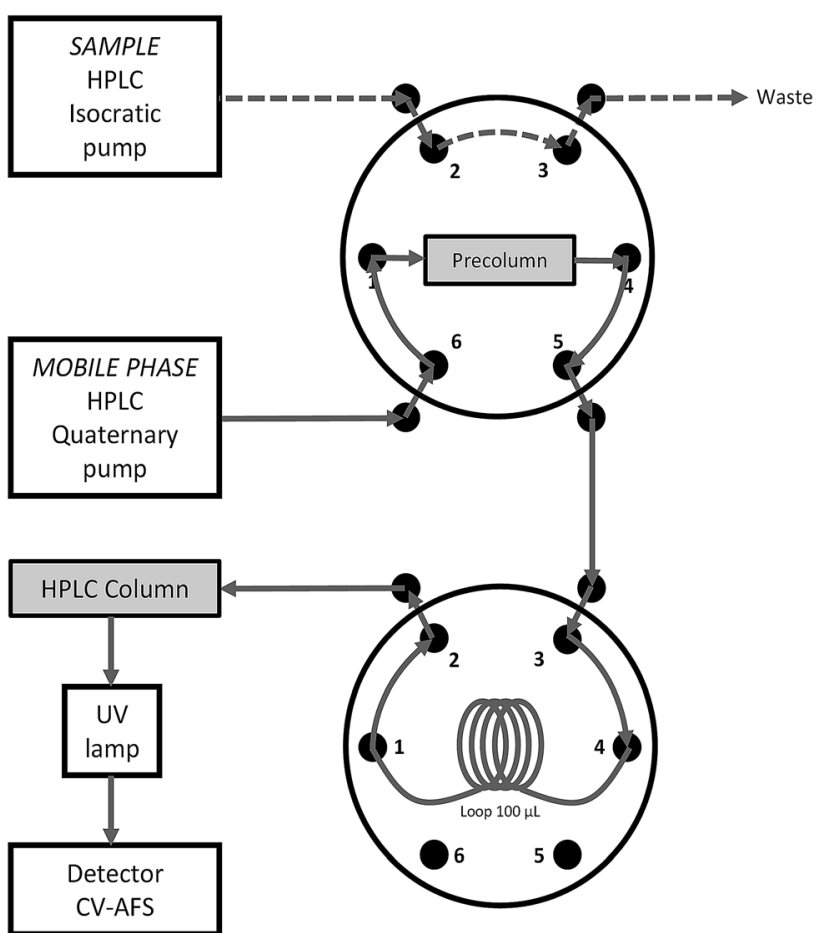

Fig. 1 Schematic representation of the online preconcentration system hyphenated to LC-UV-CV-AFS: (a) load of the sample on the precolumn, and (b) elution of the sample to the separation column. 
Fig. 1 shows a schematic diagram of the online preconcentration system coupled to LC-UV-CV-AFS for the determination of trace mercury species in water samples.

The samples were quantified by means of an external calibration curve from methylmercury and mercury(II) standards from $2.5 \mu \mathrm{g} \mathrm{L}^{-1}$ to $750 \mu \mathrm{g} \mathrm{L}^{-1}$. They were prepared by appropriate dilution in $\mathrm{MeOH}$ : APDC $80: 20$ and they were injected into the LC-UV-CV-AFS system using the $100 \mu \mathrm{L}$ loop represented in Fig. 1.

\section{Results and discussion}

To set the working standard concentration for the preconcentration studies, detection and quantification limits of the previously established LC-UV-CV-AFS method ${ }^{3}$ were assessed again under the current instrumental conditions. The detection limits (calculated as $3 \mathrm{SD}_{\mathrm{BLANK}} / \mathrm{slope} ;=23$ ) were 0.53 and 0.57 $\mu \mathrm{g} \mathrm{\textrm {L } ^ { - 1 }}$ for $\mathrm{MeHg}^{+}$and $\mathrm{Hg}^{2+}$, respectively. The quantification limits (calculated as $10 \mathrm{SD}_{\mathrm{BLANK}} /$ slope; $n=23$ ) were 1.80 and $1.90 \mu \mathrm{g} \mathrm{L}^{-1}$ for $\mathrm{MeHg}^{+}$and $\mathrm{Hg}^{2+}$, respectively. The values were of the same order of magnitude of those previously reported. The linearity range was observed to be lineal up to $750 \mu \mathrm{g} \mathrm{L}^{-1}$. $^{3}$

Different tests using several replicates of working standard solution containing mercury species at a concentration of $5 \mu \mathrm{g}$ $\mathrm{L}^{-1}$, which is slightly higher than the limit of quantification, were performed to establish the preconcentration method. Even if the preconcentration system increased the signal for the working standards, a lack of reproducibility and strong memory effects were observed. Thus, systematic studies of several variables were undertaken to assess the load volume, preconcentration factors (PFs) and recoveries. PFs were calculated as the ratio between the concentration obtained after preconcentration and the initial concentration. Recovery values were calculated as the ratio between the experimental concentration obtained and the theoretical concentration.

\section{Assessment of the preconcentration step}

Initial preconcentration tests working with standards showed a lack of reproducibility of the signal or even no detection of the species in the elution step when no complexing agent was added to the working standard solutions. Thus, the use of a complexing agent which is able to retain mercury species was studied. Two complexing agents, APDC and 2-mercaptoethanol, commonly used in the literature, ${ }^{17,22}$ were tested at concentrations $2 \mathrm{mmol} \mathrm{L}^{-1}$ and $14 \mathrm{mmol} \mathrm{L}^{-1}$, respectively. Working standard solutions of $0.05,0.5$ and $5 \mu \mathrm{g} \mathrm{L}{ }^{-1}$ of $\mathrm{MeHg}^{+}$and $\mathrm{Hg}^{2+}$ were prepared with the complexing agent, and were preconcentrated in different working sessions.

When working with APDC, the presence of low peak signals at retentions times different from those attributed to the mercury species in the separation method has been observed with a lack of reproducibility. Even if a significant retention can be achieved with APDC, an incomplete elution of the species as well as memory effects were observed. When using 2-mercaptoethanol as a complexing agent, both species were eluted at the expected retention times, with a good signal and overcoming the previous observed problems. Thus, further studies were performed using 2-mercaptoethanol as the complexing agent to establish its concentration.

The concentrations of 2-mercaptoethanol from 0.07 to 140 mmol L ${ }^{-1}$ were tested. Different sample volumes of these standard solutions were preconcentrated in three working sessions using a $1 \mathrm{~cm}$-long precolumn. When the highest concentration of 2-mercaptoethanol (140 $\mathrm{mmol} \mathrm{L}^{-1}$ ) was used, different signals that did not correspond to either $\mathrm{MeHg}^{+}$or $\mathrm{Hg}^{2+}$ were observed. These additional signals could be due to the formation of undesired complexes of $\mathrm{Hg}\left(\mathrm{CH}_{3} \mathrm{OH}\right):$ mercaptoethanol. ${ }^{37}$ The concentrations of the complexing agent from 0.07 to $14 \mathrm{mmol}$ $\mathrm{L}^{-1}$ did not show any additional signals, apart from mercury species. Fig. 2 shows the breakthrough volume obtained. As can be seen, at the lower 2-mercaptoethanol concentration, higher sample volumes could be loaded in the precolumn before achieving the breakthrough point. Consequently, higher preconcentration factors were obtained. Thus, $0.07 \mathrm{mmol} \mathrm{L}^{-1}$ was selected as the working concentration. Conditioning the precolumn with $0.07 \mathrm{mmol} \mathrm{\textrm {L } ^ { - 1 }}$ 2-mercaptoethanol caused a decrease in peak intensity, because the retention of the free thiol groups in the $\mathrm{C} 18$ precolumn decreased the amount of stationary phase available for the retention of $\mathrm{MeHg}^{+}$and $\mathrm{Hg}^{2+}$ complexes. Thus, in further experiments, the precolumn was only conditioned with the mobile phase.

The sample loading at different flows was also assessed to study the possible impact of this variable on mercury species signals. Two different sample volumes, 2 and $5 \mathrm{~mL}$, were preconcentrated at five different flows, from 1 to $5 \mathrm{~mL} \mathrm{~min}^{-1}$ using a $1 \mathrm{~cm}$-long precolumn. The peak signals obtained at 1 and 2 $\mathrm{mL} \min ^{-1}$ flow were of the same order of magnitude, but from 3 $\mathrm{mL} \min ^{-1}$ flow, the signal of both species decreased gradually. When the flow rate was increased, the contact time was not enough to achieve equilibrium between the mobile and stationary phases. Thus, $2 \mathrm{~mL} \mathrm{~min}^{-1}$ was selected for further assays.

The effect of precolumn length was studied to assess the retention capability of mercury species in the stationary phase. Three columns of different lengths were selected: 1,2 and $5 \mathrm{~cm}$.

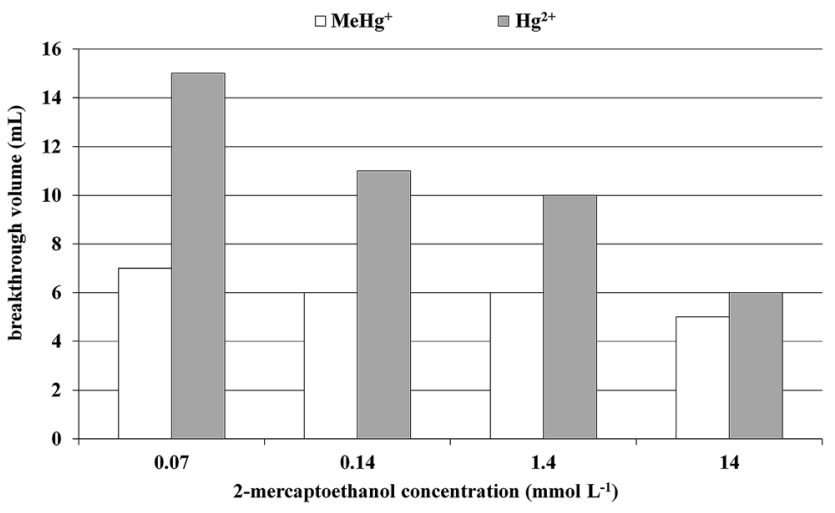

Fig. 2 Breakthrough volume obtained versus complexing agent concentration in a $5 \mu \mathrm{g} \mathrm{L}^{-1} \mathrm{MeHg}^{+}$and $\mathrm{Hg}^{2+}$ standard. Precolumn length: $1 \mathrm{~cm}$. 
Two working standard solutions of $\mathrm{MeHg}^{+}$and $\mathrm{Hg}^{2+}$ at concentrations of 0.5 and $5 \mu \mathrm{g} \mathrm{L}^{-1}$ of both species were initially prepared in $0.07 \mathrm{mmol} \mathrm{L}^{-1}$ 2-mercaptoethanol. Increasing volumes of these solutions were tested until the breakthrough point. As an example, Fig. 3 represents the mercury species concentrations obtained in the preconcentration of a given volume in working solutions of $5 \mu \mathrm{g} \mathrm{L}^{-1}$. As can be observed, the $1 \mathrm{~cm}$-long precolumn breakthrough volume for both species was lower than $8 \mathrm{~mL}$. However, in 2 and $5 \mathrm{~cm}$-long precolumns, these volumes increased up to $14-18 \mathrm{~mL}$. In all cases, the breakthrough volumes were higher for $\mathrm{Hg}^{2+}$ than for $\mathrm{MeHg}^{+}$, due to the higher affinity of this species for the C18 stationary phase.

Preconcentration factors and recoveries at the breakthrough volume including the standard deviation are plotted in Fig. 4A for both species in each precolumn. Higher preconcentration factors were obtained when 2 and $5 \mathrm{~cm}$ precolumns were used, due to the fact that their retention capability is higher than that of the $1 \mathrm{~cm}$ precolumn. Regarding percent recoveries, similar values were obtained among the three precolumns and they ranged from 60 to $80 \%$.

Even if preconcentration factors provided by 2 and $5 \mathrm{~cm}$ precolumns were suitable, the observed chromatographic behaviour of both systems was different, as shown in Fig. 4B. The direct injection of the $5 \mu \mathrm{g} \mathrm{L}^{-1}$ standard has also been included for comparison purposes. As can be seen, mercury(II) did not present Gaussian behaviour when the breakthrough volume was preconcentrated in a $5 \mathrm{~cm}$ precolumn. This effect could be because the precolumn is long enough for the mercury(II) separation process to start before the analytical column is reached. Thus, it can be concluded that a $2 \mathrm{~cm}$ column is most suitable for the preconcentration method.

\section{Application in water samples}

Once the most appropriate conditions for online preconcentration had been selected, the water samples were tested. Three water samples of increasing complexity (weak mineralisation, strong mineralisation and tap water) were characterised following the procedure described in the "Samples" section. To

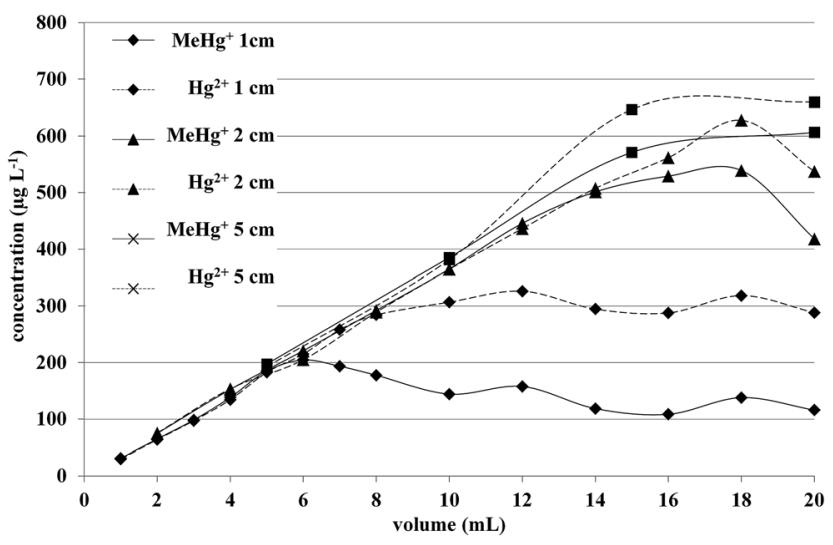

Fig. 3 Mercury species concentrations obtained versus volume preconcentrated on working solutions of $5 \mu \mathrm{g} \mathrm{L}^{-1}$.
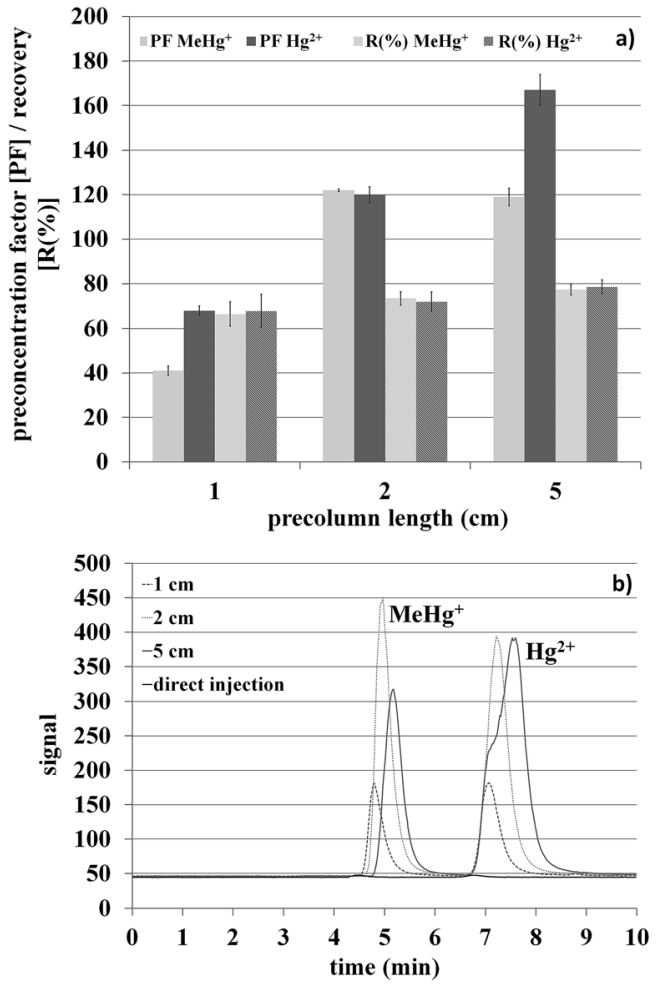

Fig. $4 \mathrm{MeHg}^{+}$and $\mathrm{Hg}^{2+}$ recoveries, preconcentration factors (A) and chromatograms obtained (B) from a $5 \mu \mathrm{g} \mathrm{L}^{-1}$ standard at the breakthrough volume in each precolumn, together with a direct injection of this standard.

ensure if the samples could have or not trace amounts of mercury, the total mercury content was determined in all matrices by ICP-MS, and the Hg content was under the detection limit $\left(0.05 \mu \mathrm{g} \mathrm{L}^{-1}\right)$. Samples were spiked at three levels: lowlevel $\left(0.5 \mu \mathrm{g} \mathrm{L}^{-1}\right.$ of both species), medium-level $\left(0.5 \mu \mathrm{g} \mathrm{L}^{-1}\right.$ of $\mathrm{MeHg}^{+}$and $5 \mu \mathrm{g} \mathrm{L}^{-1}$ of $\left.\mathrm{Hg}^{2+}\right)$ and high-level $\left(5 \mu \mathrm{g} \mathrm{L}^{-1}\right.$ of both species). The samples were then preconcentrated until the breakthrough volume was achieved for each matrix.

Due to a matrix effect, both breakthrough volumes and preconcentration factors were lower in water samples $(\approx 7 \mathrm{~mL}$ and $\approx 50$, respectively) than in double deionised water $(16 \mathrm{~mL}$ and $\approx 120$, respectively). This effect may be due to a possible competition of other substances present in water samples in addition to mercury with the precolumn stationary phase, which can lead to a decrease in its retention capacity. However, recovery values of both species were of the same order of magnitude as those previously described in the "Precolumn length" section and ranged from 67 to $86 \%$, regardless of the type of water, which may indicate that this parameter is independent of the matrix composition. Higher $\mathrm{PF}$ and recoveries for $\mathrm{Hg}^{2+}$ were also observed.

From the data obtained, it was considered that the most suitable breakthrough volume for routine analysis is that obtained for the most complex matrix (tap water) and for the least retained species $\left(\mathrm{MeHg}^{+}\right)$, which are the worst retention conditions: $4 \mathrm{~mL}$. This volume allows us to work under reproducible conditions with good recoveries, regardless of the type of sample and concentration levels. 
Table 2 shows the preconcentration factor, recovery, mean values and standard deviation for a $4 \mathrm{~mL}$ preconcentration volume. The overall average represents the mean of each replicate. The PF values were $30 \pm 1$ and $32 \pm 3$ for $\mathrm{MeHg}^{+}$and $\mathrm{Hg}^{2+}$, respectively. The recovery values were $72 \% \mathrm{MeHg}^{+}$and $81 \%$ for $\mathrm{Hg}^{2+}$ and the RSD mean values were below 15\%. As it can be seen, methylmercury recoveries are always lower than those obtained for $\mathrm{Hg}^{2+}$. The possible justification for this behaviour is that $\mathrm{MeHg}^{+}$-mercaptoethanol complexes present less affinity for $\mathrm{C} 18$ than the $\mathrm{Hg}^{2+}$ ones. The higher affinity of $\mathrm{Hg}^{2+}$ for the $\mathrm{C} 18$ could be due to the stoichiometry of the formed complex. $\mathrm{Hg}^{2+}$ forms $1: 2$ complexes with 2-mercaptoethanol and APDC whereas $\mathrm{MeHg}^{+}$forms $1: 1$ complexes. The 1:2 complex presents more retention in C18 than the $1: 1$ complex because it has more sulphur atoms in the structure, which are mainly responsible for the retention process in C18.

Considering that the waters that were analysed had different matrices, the standard deviations obtained were suitable and the similarity between the PF and recovery values demonstrates the robustness of the established conditions for the online preconcentration system.

Thus, Table 3 summarises the optimum conditions for the determination of $\mathrm{MeHg}^{+}$and $\mathrm{Hg}^{2+}$ by LC-UV-CV-AFS following online preconcentration.

\section{Analytical figures of merit}

Accuracy. The accuracy of the method was assessed by the analysis of a certified reference material (CRM). To our knowledge

Table 2 Preconcentration parameters obtained for each species in water samples for a $4 \mathrm{~mL}$ preconcentration volume

\begin{tabular}{|c|c|c|c|c|}
\hline Species & Sample (water) & $\mathrm{PF}^{a}$ & Recovery $^{b}(\%)$ & $\operatorname{RSD}^{b}(\%)$ \\
\hline \multirow[t]{4}{*}{$\mathrm{MeHg}^{+}$} & Double deionised & $29 \pm 2$ & $73 \pm 5$ & 2 \\
\hline & Weak mineralised & $30 \pm 2$ & $74 \pm 6$ & 8 \\
\hline & Strong mineralised & $30 \pm 1$ & $67 \pm 9$ & 13 \\
\hline & Tap & $27 \pm 4$ & $74 \pm 2$ & 2 \\
\hline \multicolumn{2}{|c|}{ Overall average } & $30 \pm 1$ & $72 \pm 3$ & 4 \\
\hline \multirow[t]{4}{*}{$\mathrm{Hg}^{2+}$} & Double deionised & $32 \pm 2$ & $80 \pm 4$ & 5 \\
\hline & Weak mineralised & $34 \pm 1$ & $86 \pm 4$ & 5 \\
\hline & Strong mineralised & $34 \pm 2$ & $84 \pm 5$ & 6 \\
\hline & Tap & $35 \pm 5$ & $87 \pm 9$ & 10 \\
\hline \multicolumn{2}{|c|}{ Overall average } & $32 \pm 3$ & $81 \pm 5$ & 6 \\
\hline
\end{tabular}

${ }^{a}$ Preconcentration factor. ${ }^{b} n=3$.

Table 3 Final selected conditions for online preconcentration of $\mathrm{MeHg}^{+}$and $\mathrm{Hg}^{2+}$ by LC-UV-CV-AFS

Optimum conditions

Precolumn conditioning

Complexing agent

Sample flow

Precolumn length

Preconcentration volume
Mobile phase $0.07 \mathrm{mmol} \mathrm{L}^{-1}$ 2-mercaptoethanol

$2 \mathrm{~mL} \mathrm{~min}^{-1}$

$2 \mathrm{~cm}$

$4 \mathrm{~mL}$ there are no CRMs for $\mathrm{Hg}^{2+}$ and $\mathrm{MeHg}^{+}$species in natural waters. Most of the CRMs available for total mercury consist of spiked water samples. ${ }^{7}$ To evaluate the preconcentration method, the most suitable CRMs would be water with a total mercury level close to the limit of quantification of the analytical technique without the preconcentration step. It was found only wastewater with certified values for the total content of 10 elements including mercury (ERM-CA713, $1.84 \pm 0.11 \mu \mathrm{g} \mathrm{Hg} \mathrm{L}^{-1}$ ). The total $\mathrm{Hg}$ content was analysed in the CRM by CV-AFS, which provided a mercury concentration of $1.81 \pm 0.03 \mu \mathrm{g} \mathrm{L} \mathrm{L}^{-1}(n=3)$. No significant difference was found between the certified and experimental total content ( $t$-test at 95\% confidence level).

Mercury species in the CRM were analysed by direct injection and after the online preconcentration step, using the previously established optimised conditions. A total of $4 \mathrm{~mL}$ of wastewater were preconcentrated and the PFs obtained in section "Application in water samples" (see Table 2) were applied. The analyses were performed in triplicate.

Table 4 summarises the results obtained by the two speciation methods. Regarding the direct injection method, the concentration of methylmercury was below the limit of detection, whereas the concentration of mercury(II) in the CRM was close to the limit of quantification.

In the preconcentration method, both species were well quantified. Regarding the sum of species, a $t$-test (95\% confidence level) was performed with respect to the certified value. No significant difference was found. The results show that the preconcentration method can quantify all mercury species, and their sum can be used to determine the total mercury content in water.

Limits of detection and quantification. Limits of detection and quantification for the online preconcentration method were assessed experimentally by injecting standard solutions from 1 to $500 \mathrm{ng} \mathrm{L}{ }^{-1} \cdot \mathrm{Hg}^{2+}$ was detected at about $2 \mathrm{ng} \mathrm{\textrm {L } ^ { - 1 }}$ whereas $\mathrm{MeHg}^{+}$was detected at about $15 \mathrm{ng} \mathrm{\textrm {L } ^ { - 1 }}$. Experimental limits of quantification were $50 \mathrm{ng} \mathrm{\textrm {L } ^ { - 1 }}$.

Limits of detection and quantification concentrations were considerably lower than those obtained by the direct injection method: values were in the order of $\mu \mathrm{g} \mathrm{L}^{-1}$, compared to values

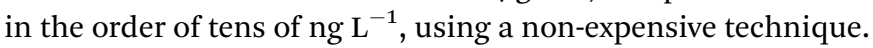

However, the preconcentration of samples with a low complexity matrix would decrease the limits of detection and quantification in the online preconcentration method, by using a higher load volume.

Table 4 Methylmercury and mercury(II) concentrations obtained in ERM-CA713 (certified value: $1.84 \pm 0.11 \mu \mathrm{g} \mathrm{Hg} \mathrm{L}^{-1}$ ) by direct injection and online preconcentration

\begin{tabular}{llllll}
\hline & \multicolumn{2}{l}{ Direct injection } & & \multicolumn{2}{l}{$\begin{array}{l}\text { Online } \\
\text { preconcentration }\end{array}$} \\
\cline { 2 - 3 } Species & $C\left(\mu \mathrm{g} \mathrm{L}^{-1}\right)$ & $\mathrm{RSD}(\%)$ & & $C\left(\mu \mathrm{g} \mathrm{L}^{-1}\right)$ & $\mathrm{RSD}(\%)$ \\
\hline $\mathrm{MeHg}^{+}$ & LD & - & & $0.28 \pm 0.01$ & 2.9 \\
$\mathrm{Hg}^{2+}$ & $1.71 \pm 0.02$ & 1.2 & & $1.72 \pm 0.06$ & 3.6 \\
Sum of species & $1.71 \pm 0.02$ & 1.2 & & $2.00 \pm 0.06$ & 3.0
\end{tabular}

$1.71 \pm 0.02 \quad 1.2$ 


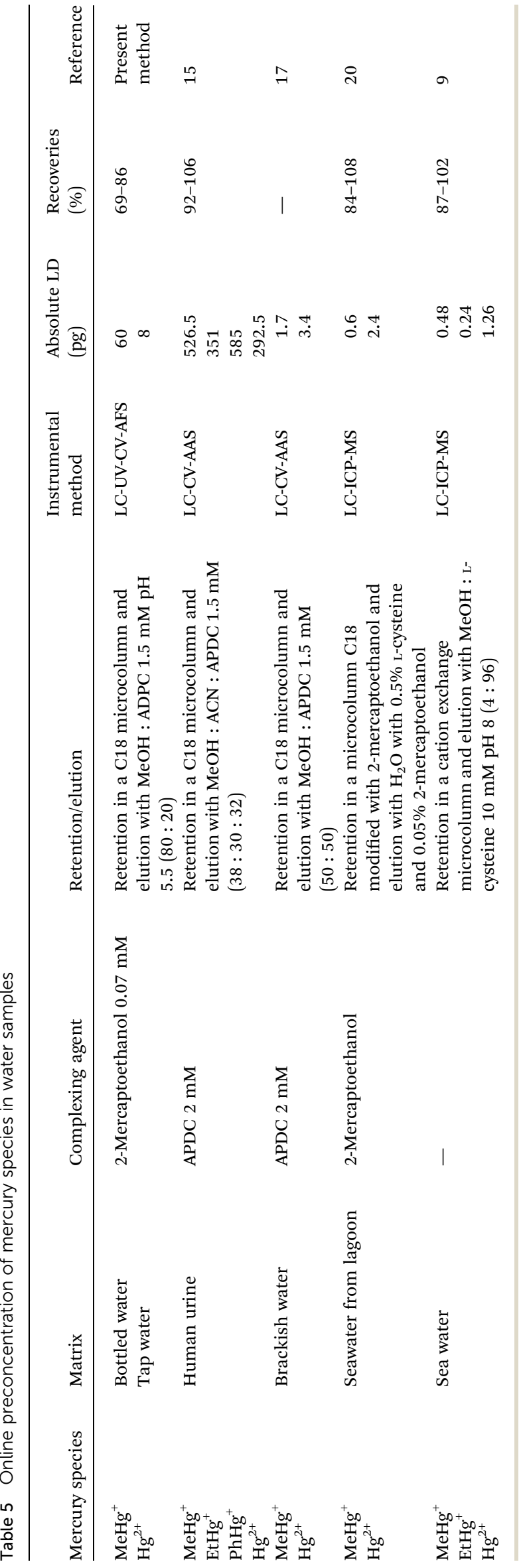

Table 5 compares the detection limits and recoveries obtained in this paper with those previously reported in the literature using a similar methodology. The recoveries obtained are comparable, and the detection limits are of the same order of magnitude when the total amount of mercury detected is considered. As expected, the detection limits obtained by ICPMS are lower than those obtained by AAS or AFS. Nevertheless, CV-AFS provides suitable analytical performance, which is userfriendly and requires lower investment and maintenance costs than ICP-MS, so it is a good approach in daily routine laboratory analysis.

\section{Conclusions}

An online preconcentration method for $\mathrm{MeHg}^{+}$and $\mathrm{Hg}^{2+}$ determination, the most relevant mercury species present in the environment, was developed using a $2 \mathrm{~cm}$ ODS Hypersil (C18; reverse phase) precolumn in the preconcentration step. These precolumns are commercially available and widely used in routine laboratory analysis. The method requires a low volume $(4 \mathrm{~mL})$ and a simple sample pre-treatment (addition of 2-mercaptoehtanol $0.07 \mathrm{mmol} \mathrm{L}^{-1}$ ). The online preconcentration-LCUV-CV-AFS system provides recoveries of $72 \pm 3 \%$ and $81 \pm 5 \%$ for $\mathrm{MeHg}^{+}$and $\mathrm{Hg}^{2+}$, respectively, which were obtained regardless of the matrix composition.

The sum of the species in the proposed method matched with the total mercury content. The limits of detection and quantification established are suitable for analytical performance using environmental samples. Thus, the method is widely applicable, highly precise and accurate, and could be useful for $\mathrm{MeHg}^{+}$and $\mathrm{Hg}^{2+}$ determination, in response to any future legislation on mercury species.

\section{Acknowledgements}

We thank the DGCYT (project number CTQ2010-15377/BQU) and the Grup de Recerca Consolidat (project number SGR20091188) for financial help received in support of this study. The authors also thank Dr Toni Padró (Serveis Científic Tècnic Universitat de Barcelona) for support in ICP-MS.

\section{References}

1 United Nations Environment Programme (UNEP), Global Mercury Assessment 2013: Sources, Emissions, Releases, and Environmental Transport, Geneva, 2013.

2 Trace Element Speciation for Environment, Food and Health, ed. L. Ebdon, L. Pitts, R. Cornelis, H. Crews, O. F. X. Donard and P. Quevauviller, Royal Society of Chemistry, Cambridge, 2001.

3 C. Ibáñez-Palomino, J. F. López-Sánchez and A. Sahuquillo, Int. J. Environ. Anal. Chem., 2012, 92, 909-921.

4 I. Lehnherr, V. L. St. Louis, H. Hintelmann and J. L. Kirk, Nat. Geosci., 2011, 4, 298-302.

5 Directive 2008/105/EC of the European Parliament and of the Council of 16 December 2008 on environmental quality standards in the field of water policy. 
6 Directive 98/83/EC of the Council of 3 November 1998 on the quality of water intended for human consumption.

7 C. Ibáñez-Palomino, J. F. López-Sánchez and A. Sahuquillo, Anal. Chim. Acta, 2012, 720, 9-15.

8 S. Martínez-Trinidad, G. Hernández Silva, M. E. Ramírez Islas, J. Martínez Reyes, G. Solorio Munguía, S. Solís Valdez and R. García Martínez, Geofis. Int., 2013, 52-1, 43-58.

9 X.-Y. Jia, D.-R. Gong, Y. Han, C. Wei, T.-C. Duan and H.-T. Chen, Talanta, 2012, 88, 724-729.

10 H. Hintelmann and R.-D. Wilken, Appl. Organomet. Chem., 1993, 7, 173-180.

11 S. Río-Segade, Talanta, 1999, 48, 477-484.

12 L.-N. Liang, G.-B. Jiang, J.-F. Liu and J.-T. Hu, Anal. Chim. Acta, 2003, 477, 131-137.

13 J. L. Gómez-Ariza, F. Lorenzo and T. García-Barrera, J. Chromatogr. A, 2004, 1056, 139-144.

14 S. S. Bozkurt, K. Ocakoglu and M. Merdivan, Microchim. Acta, 2011, 177, 47-52.

15 X. Yin, W. Frech, E. Hoffmann, C. Lüdke and J. Skole, Fresenius. J. Anal. Chem., 1998, 361, 761-766.

16 R. M. Blanco, M. T. Villanueva, J. E. S. Uría and A. SanzMedel, Anal. Chim. Acta, 2000, 419, 137-144.

17 J. Qvarnström, Q. Tu, W. Frech and C. Lüdke, Analyst, 2000, 125, 1193-1197.

18 D. Sánchez, Talanta, 2000, 52, 671-679.

19 S. R. Segade and J. F. Tyson, Talanta, 2007, 71, 1696-1702.

20 W. R. L. Cairns, M. Ranaldo, R. Hennebelle, C. Turetta, G. Capodaglio, C. F. Ferrari, A. Dommergue, P. Cescon and C. Barbante, Anal. Chim. Acta, 2008, 622, 62-69.

21 T. Hashempur, M. K. Rofouei and A. R. Khorrami, Microchem. J., 2008, 89, 131-136.
22 J. Margetínová, P. Houserová-Pelcová and V. Kubán, Anal. Chim. Acta, 2008, 615, 115-123.

23 H. Ashkenani, S. Dadfarnia, A. M. H. Shabani, A. A. Jaffari and A. Behjat, J. Hazard. Mater., 2009, 161, 276-280.

24 Y. Yin, M. Chen, J. Peng, J. Liu and G. Jiang, Talanta, 2010, 81, 1788-1792.

25 H. Emteborg, D. C. Baxter and W. Frech, Analyst, 1993, 118, 1007.

26 H. Bagheri, Talanta, 2001, 55, 1141-1150.

27 M. Garrido, M. S. Di Nezio, A. G. Lista, M. Palomeque and B. S. Fernández Band, Anal. Chim. Acta, 2004, 502, 173-177.

28 H. Wu, Y. Jin, W. Han, Q. Miao and S. Bi, Spectrochim. Acta, Part B, 2006, 61, 831-840.

29 B. R. Vermillion and R. J. M. Hudson, Anal. Bioanal. Chem., 2007, 388, 341-352.

30 M. Tuzen, O. D. Uluozlu, I. Karaman and M. Soylak, J. Hazard. Mater., 2009, 169, 345-350.

31 M. Tuzen, I. Karaman, D. Citak and M. Soylak, Food Chem. Toxicol., 2009, 47, 1648-1652.

32 Y. Gao, W. Yang, C. Zheng, X. Hou and L. Wu, J. Anal. At. Spectrom., 2011, 26, 126.

33 C.-M. Tseng, C. R. Hammerschmidt and W. F. Fitzgerald, Anal. Chem., 2004, 76, 7131-7136.

34 M. V. Balarama Krishna, K. Chandrasekaran and D. Karunasagar, Talanta, 2010, 81, 462-472.

35 A. R. Türker, D. Çabuk and Ö. Yalçınkaya, Anal. Lett., 2013, 46, 1155-1170.

36 F. Moreno, T. García-Barrera and J. L. Gómez-Ariza, J. Chromatogr. A, 2013, 1300, 43-50.

37 M. V. Balarama Krishna, J. Castro, T. M. Brewer and R. K. Marcus, J. Anal. At. Spectrom., 2007, 22, 283. 